\title{
Weizmann finance chief embezzled \$5 million
}

Haim Watzman, Jerusalem

An official at the Weizmann Institute of Science has confessed to pocketing US $\$ 5$ million from one of the institute's fundraising organizations in Europe.

Israeli police say that some of the money, taken from the Zurich-based European Committee of the Weizmann Institute of Science, was channelled through the GSI, a national research institute in Darmstadt, Germany.

The Weizmann Institute in Rehovot is Israel's leading multidisciplinary research institute. It called in the police to investigate the activities of its finance division chief, Michael Netzer, in July. An employee at Bank Leumi in Zurich, where the European committee has an account, had notified the bank's branch in Rehovot of suspicious financial transactions.

According to a police spokesman, Netzer said that he invested $\$ 1.5$ million of the money in the stock market and used most of the rest to fund a gambling addiction. Netzer, whom the police have decided not to detain because of ill health, claims that he also used money to pay for medical procedures he needed.

The fund-raising European committee is one of several 'friends of' organizations that raise money for the Weizmann Institute around the world. Government funding covers only part of the institute's annual outlay,

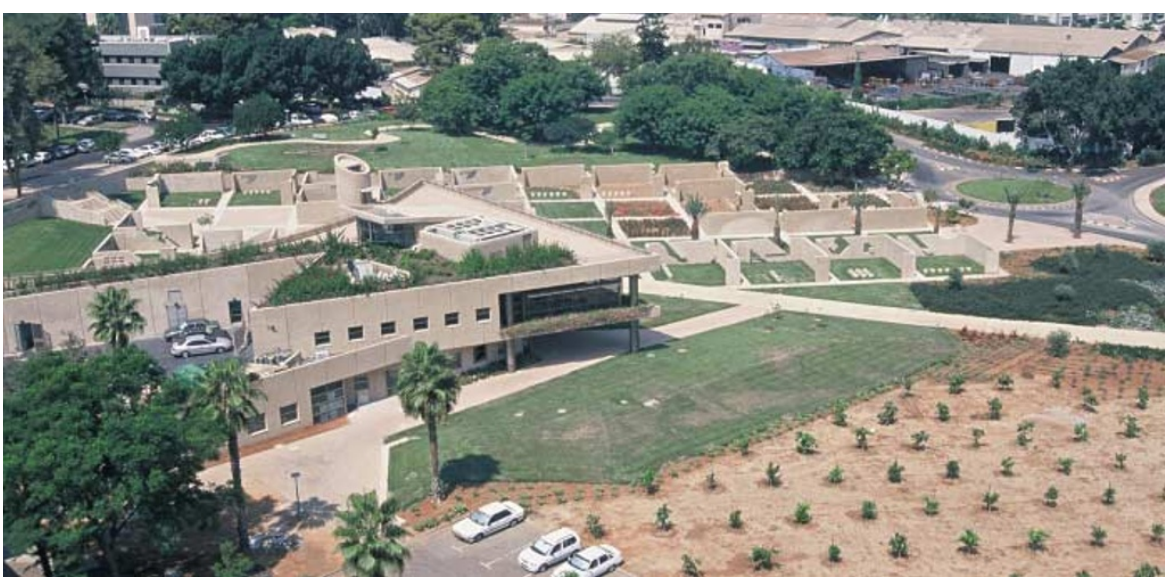

Out of pocket: the Weizmann Institute called in the police to search for its missing millions.

and much of the remainder comes from funds raised overseas.

The European committee also holds an account in the Rehovot branch of Bank Leumi, where Netzer was one of four people with signing authority.

A subsequent audit of the Rehovot account revealed that Netzer deposited some of the money, which he claimed was 'private', into the personal account of the GSI's administrative director, who in turn made cash payments to Netzer. The administrative director was not available for comment, but Walter Henning, the scientific director of the GSI, says he sees no reason to conduct an investigation at the institute.

Little information is emerging from the Weizmann Institute itself. Yivsam Azgad, an institute spokesman, has confirmed that the institute started the police investigation at the request of the European committee, which is legally an independent body.

Azgad states only that "a small part of the committee's funds were transferred to unidentified accounts" and that "a significant portion of these funds have already been returned". He added that the institute's investigation of the matter revealed "further irregularities", in the wake of which Netzer resigned from his post.

\section{Public library set to turn publisher as boycott looms}

\section{Declan Butler}

The Public Library of Science (PLS), a grassroots initiative that has called for a boycott of scientific publishers, says that it is considering publishing journals itself.

Announced only three weeks before the boycott is due to begin, this is the next step in the library's campaign to promote free access to literature.

More than 25,000 scientists signed the PLS open letter, in which they pledged to stop buying, publishing in, or reviewing for any journal that refuses to place its research papers in free online archives six months after publication.

Michael Eisen, a geneticist at the University of California, Berkeley, and one of the leaders of the PLS initiative, says that one of the main goals of the campaign was to stimulate publishers into experimenting with business models other than the traditional 'reader pays' arrangement.

But most publishers seem uninterested, says Eisen, and the PLS has therefore "somewhat reluctantly" concluded that it will

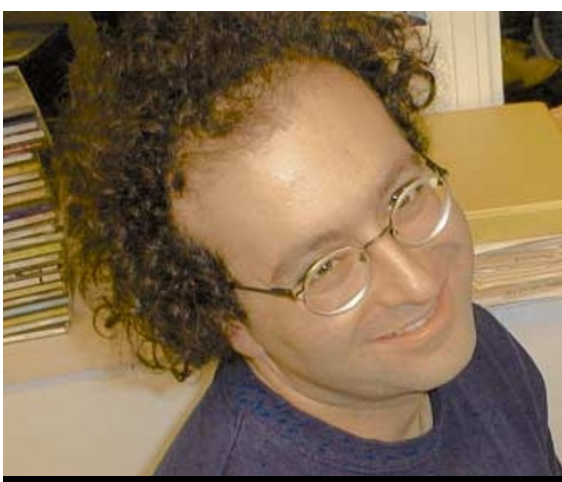

Access all areas: Michael Eisen says he wants a 'positive option' for online science publishing.

probably need to create its own publishing system, to show the economic viability of alternatives and to provide the scientists who have supported its campaign with a place to publish that provides free access.

For the moment, the PLS has few detailed plans about how it would put such a scheme into practice, but says that it has discussed the idea with many of the signatories of the open letter with a view to soliciting reviewers. Under its initial proposals for the scheme, all journals would be published online only, with page charges and institutional charges covering the estimated cost of US\$200-500 per manuscript.

With the September boycott deadline looming, the PLS is under pressure to maintain the movement's momentum. "A boycott is a negative thing. People have careers and need to publish; we want those who have supported the initiative to have a positive option supporting a new publishing venture," Eisen says.

The PLS does not expect that signatories will adhere to the boycott pledge to the letter. "People didn't sign to be dogmatic, but they share a goal and will back these up with reasonable action," says Eisen.

Although running close to its deadline, the PLS is open to discussing ways of moving forwards, Eisen adds. "A slight delay of a month or two in the boycott would be okay; any longer and we will lose the momentum." 